\title{
CHARACTERIZATION OF COAL FROM BAYANTEEG DEPOSIT
}

\author{
Batbileg S. ${ }^{*}$, Purevsuren B. ${ }^{1}$, Dabaajav Ya. ${ }^{1}$, Batkhishig D. ${ }^{1}$, \\ Namkhainorov J. ${ }^{1}$, Battsetseg M. ${ }^{1}$ and Narangerel J. ${ }^{1}$ \\ 1 Laboratory of Coal Chemistry, Institute of Chemistry and Chemical Technology, \\ Mongolian Academy of Sciences \\ *corresponding author: e-mail: bilegsanjaa@gmail.com
}

\begin{abstract}
The coal of Bayanteeg deposit was investigated and its technical characteristics, elemental and petrographical maceral compositions were determined. On the basis of proximate, ultimate, petrographic analyses results, it has been confirmed that the Bayanteeg coal is a middle-rank D mark subbituminous coal. The pyrolysis of Bayanteeg coal was studied by using a standard quarts retort (tube) at different heating temperatures and the yields of pyrolysis products such as hard residue, tar, pyrolytic water and gas were determined. The result of these experiments showed that the higher yield 14\% of tar can be obtained at heating temperature $500^{\circ} \mathrm{C}$.

Also the thermal dissolution of Bayanteeg coal was investigated by using a standard stainless steel autoclave at different heating temperatures and the yields of pyrolysis poroducts such as hard residue, tar, pyrolytic water and gas were determined. The tetralin was used as hydrogen donor solvent with constant mass ratio between coal and tetralin (1:1.8). The results of these experiments showed that high yield of tar $48 \%$ can be obtained on thermal dissolution of the coal organic mass at $450^{\circ} \mathrm{C}$. The solubility of purified pyrolysis tar of Bayanteeg coal in hexane, benzene and dichloromethane was investigated by using silica gel column and the chemical composition of each fraction was determined by using of GC/MS chromatograph system.
\end{abstract}

KEYWORDS: petrographic analysis, pyrolysis, thermal dissolution, donor solvent;

\section{INTRODUCTION}

Mongolia is one of the world coal rich countries with possible resource of 175 billion ton [1]. Coal resources are distributed in all provinces in Mongolia. Unfortunately there are only few coal deposits including SaikhanOvoo, Ereen and Bayanteeg in the central area of Khangai mountain. The Bayanteeg coal is most exploited one in this area [2]. Early 1980 doctor Ts. Tsedevsuren et all. have investigated hydrogenation of Bayanteeg coal
[3]. The Bayanteeg coal deposit locates in the Nariinteel village of Uburkhangai aimak (central part of Mongolia), it is $130 \mathrm{~km}$ from the Uburkhangai aimak and $560 \mathrm{~km}$ from Ulaanbaatar [2].

The estimated coal resource of Bayanteeg deposit is 29.6 million ton at several coal layers with thickness of 14-22 meters. This deposit is about $25 \mathrm{~km}$ from the main asphalt road from Ulaanbaatar to Bayankhongor province. This 
is an open-cast mine and the coal is using for local energy demands of Uburkhangai, Bayankhongor and Arkhangai aimaks. The main transport of coal is performing by trucks, because it is far from railway and big cities. In 2015 there was exploited about 125000 ton of coal for the local energy needs. For this reason the coal of Bayanteeg deposit is not planed

\section{EXPERIMENTAL}

The analytical samples of coals from deposits prepared according to Mongolian National Standards (MNS 895-79) and main technical specifications including moisture (MNS 0655-79), ash (MNS 0654-79), volatile matter (MNS 0654-79), caloric value (MNS 0669-87), sulphur content (MNS ISO 351:2001), carbon and hydrogen content MNS ISO609:2003 have been determined.

Petrographic analysis was performed on polished particulate mounts following recommendations by the International Committee for Coal and Organic Petrology (ICCP). Vitrinite reflectance was measured using an Axio Imager M2m microscope (Zeiss, Germany) and Fossil software (Hilgers, Germany) on 50 individual vitrinite macerals in random mode. In addition, fluorescence microscopy was used for rapid qualitative information on maturity and organofacies. Resedimented vitrinite particles are characterized by higher reflectivity than autochthonous vitrinite. Only the vitrinite population with the lowest reflectance values was measured and reported. Maceral group analysis was performed using the same microscope and software by point counting of 500 individual macerals [8]. The method of preparation of polished coal sample for petrographic analysis as follows: 2-3 g. of analytical sample of coal, bisphenol-A (polymer binding material) and catalyst (mass ratio bisphenol-A:catalyst $=9: 3$ ) put in to a plastic vessel and mixed well. The homogenized mixture was cured at $35^{\circ} \mathrm{C}$ for $11 \mathrm{~h}$. The cured sample was polished by Tegra for future coal processing technology and the coal is not investigated in detail for example the pyrolysis and thermolysis experiments are not performed yet [4-5].Therefore the coal of Bayanteeg deposit was a subject for detailed investigation on characterization and thermal processing such as pyrolysis and thermolysis experiments.

Force-5 tool of Struers firm. The surface of polished sample applied objectiv-50/1.0 P oil and maceral group and vitrinite reflectance $\left(R V_{t}\right)$ counted at sign light of oil by microscope made in ZEISS company and performed analysis by a Fossil program [8].

The pyrolysis experiments of coal samples were performed in a laboratory vertical cylindrical retort made by stainless steel which could contain $1 \mathrm{~g}$ of sample. The retort was placed in an electric furnace (model SNOL) with a maximum temperature of $950^{\circ} \mathrm{C}$. A chrome-alumel thermocouple was inserted in the coal bed to measure the actual heating temperature. The retort was connected with a air-cooled iron tube and water-cooled laboratory glass condenser and a collection vessel for the condensate of liquid product (pitch and pyrolysis water). The non-condensable gases after water-cooled condenser were left the system through a thin glass tube. The experiments were carried out to $700^{\circ} \mathrm{C}$ temperature and the heating rate was $20^{\circ} \mathrm{Cmin}-1$. The yields of products including solid residue (coal char), tar and pyrolysis water determined by weighing, and the yield of gases by differene [9].

The thermal dissolution of coal samples have been carried out in a laboratory standard stainless steel autoclave by using of tetralin as a hydrogen donor solvent [6]. Air dried for $24 \mathrm{~h}$. and powdered to a particle size < $0.2 \mathrm{~mm} 1 \mathrm{~g}$. coal sample mixed with $1.8 \mathrm{~g}$. tetralin (mass ratio 1:1.8) in autoclave and heated in a laboratory furnace at temperatures of $350,400,450^{\circ} \mathrm{C}$ for 2 hour. After completion 
of experiment the autoclave with sample cooled at room temperature and removed all uncondensed gas and resulting liquid products were filtered, and the solid residue on filter was subjected to sequential extraction with chloroform in a Soxhlet apparatus. An extract of liquid products of thermal dissolution of coal in tetralin was distilled by a laboratory rotary evaporation apparatus for complete removing of chloroform. The degree of coal conversion was determined from the loss of the organic matter of coal (COM) after extraction and also change in the ash contents of the initial coal samples and the insoluble residue.

The liquid condensed by-product of coal pyrolysis consists from tar and pyrolysis water. They form an unmixed two layers and can be separated easily by separating glass funnel. The upper layer is tar (viscous liquid) with blackbrown color and bed smell. The bottom layer is pyrolysis water (non viscous liquid) with bed smell and brown color. The final cleaning of tar from the pyrolysis water residue usually use thermally treated $\mathrm{CaCl}_{2}$ by mixing and separating (filtering or centrifuging).

The column chromatography conditions of pyrolysis tar of Bayanteeg coal as follows:

- Small glass column: $5.0 \mathrm{ml}$

- Sample of tar 0.2g. for each solvent

- Used organic solvents (pure for

\section{RESULTS AND DISCUSSION}

The results of ultimate and proximate analysis of coal samples from Bayanteeg deposits have been determined according to chromatography): hexane, benzene and dichlorometane-20,0 $\mathrm{ml}$ from each solvent.

- Used sorbent: activated silicagel 4.0g.

The column chromatography carried out for obtaining of the soluble in hexane $(\mathrm{H})$, benzene (B) and dichloromethane (M) fractions of the pyrolysis tar. These fractions were used as a mother solutions for GC/MS analysis. The organic solvent was evaporated from the obtained fraction for the determination of the yield of each fraction.

The conditions of GC/MS analysis of each fractions are:

- The analytical sample of each fraction: 1 microlitter of each fraction in $1 \mathrm{ml}$ of each solvent.

- The sample of of GC/MS analysis: 1 microlitter from each analytical sample.

- Used apparatus: Agilent 7890A Agilent 5975C GCMS system and capillary column JW DB-5,30mx, $0.25 \mathrm{~mm}$ I.D. $0.25 \mu \mathrm{m}$ (122-5032).

- Carrier gas: He

- Mass range: 50-550.

- Starting temperature of furnace: $100^{\circ} \mathrm{C}$.

- Heating temperature and time: $220^{\circ} \mathrm{C}$, 46 min.

Table 1. Proximate and Ultimate analysis of Bayanteeg coal

\begin{tabular}{|c|ccccccccc|}
\hline Coal sample & \multicolumn{4}{|c|}{ Proximate analysis, \% } & \multicolumn{4}{c|}{ Ultimate analysis, \% } \\
\hline \multirow{2}{*}{ Bayanteeg } & $\mathrm{W}^{\mathrm{a}}$ & $\mathrm{A}^{\mathrm{d}}$ & $\mathrm{V}^{\text {daf }}$ & $\mathrm{Q}^{\text {daf }}$ & $\mathrm{St}$ & $\mathrm{C}^{\text {daf } \%}$ & $\mathrm{H}^{\text {daf } \%}$ & $\mathrm{~N}^{\text {daf }}, \%$ & $\mathrm{O}^{\text {daf }}, \%$ \\
& 3.34 & 12.16 & 47.49 & 7310.0 & 0.49 & 78.23 & 5.60 & 1.55 & 14.13 \\
\hline
\end{tabular}

The yield of volatile matter $47.49 \%$, calorific value $\mathrm{Q}^{\mathrm{daf}} 7310 \mathrm{kcal} / \mathrm{kg}$ (Table 1) and elemental composition C-78.23\%, H-5.60\% show that the coal of Bayanteeg deposit is characterizing as a middle rank coal of $\mathrm{D}$ mark. The content of the above mentioned standard methods and are given in (Table 1). sulphure is lower, which is an environmentally friendly indication.

First time petrographic analysis of Bayanteeg coal have been carried out on polished coal samples using the a microscope 
connected with photoapparatus and software by point counting of 500 individual macerals. The white-black and colored petrographic

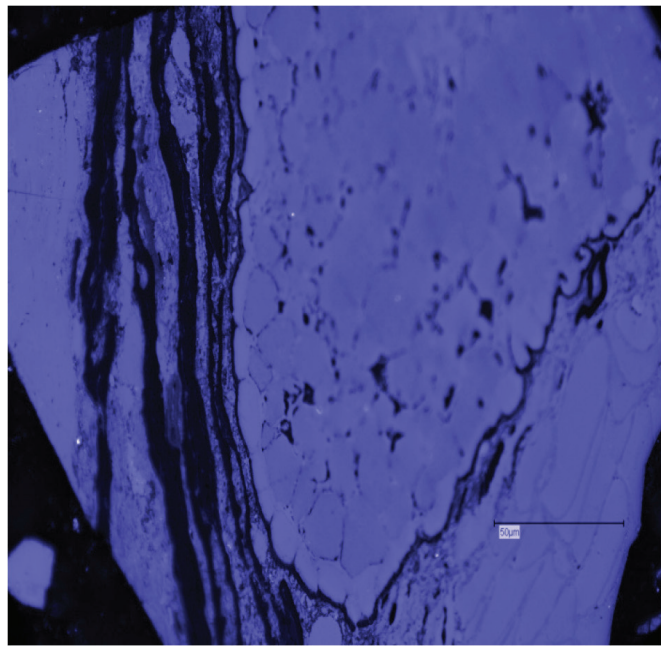

A photographs are presented in Figure1 and the maceral group (vitrinite, inertinite and liptinite) composition is given in (Table) 2 .

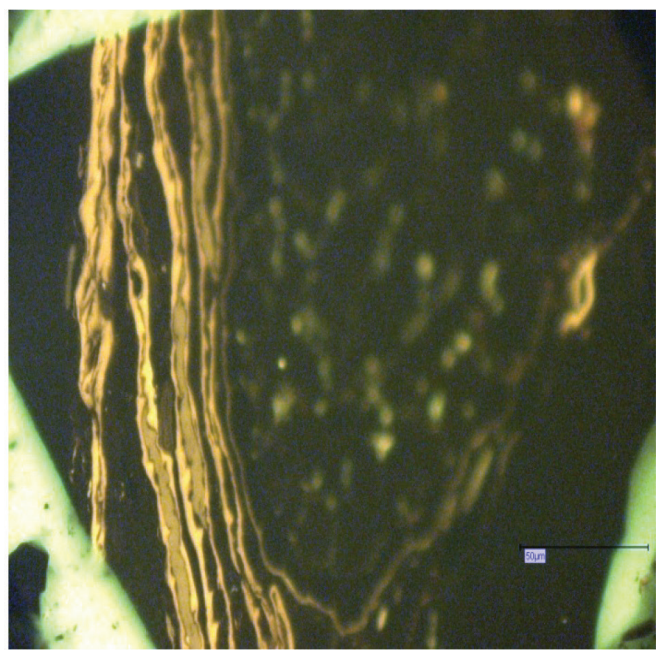

$B$

Fig. 1. The black-white (A) and coloured (B) petrographic photographs of polished coal sample of Bayanteeg deposit.

The vitrinites are grey coloured fragments with different sizes and the inertinites are white coloured stripes in white-black photograph (Fig.1. A). But the liptinites are not observed in black-white photograph (Fig.1. A) and they are yellow coloured stripes in coloured photograph (Fig.1.B). The vitrinite's fragments are black coloured in coloured photograph
(Fig.1. B). The polymeric (epoxide) binder is a black coloured background in black-white photograph (Fig.1. A) and a green coloured background in coloured photograph (Fig.1.B). The minerals in the polished coal sample are observed as a brilliant pieces in the microscope, but they are absent in black-white (A) and coloured (B) petrographic photographs.

Table 2. Petrographic analysis results, \% of Bayanteeg coal.

\begin{tabular}{|lccccc|}
\hline Coal sample & $R_{V t}$ & Vitrinite & Liptinite & Inertinite & Minerals \\
\hline Bayanteeg & 0.484 & 86.00 & 7.00 & 1.00 & 6.00 \\
\hline
\end{tabular}

The maceral group composition in (Table 2) show that the organic matter of Bayanteeg coal characterizes with highest content of vitrinite and lowest content of inertinite, liptinite and minerals connected with coal organic mass. The degree of vitrinite reflectance $\left(\mathrm{RV}_{\mathrm{t}}\right.$ $=0.484 \%$ ) was measured using an Axio Imager M2m microscope and Fossil software on 50 individual vitrinite macerals in random mode
(Fig.2). This value $0.484 \%$ is characteristic for a middle rank sub-bituminous coal. Therefore the results of determined technical characteristics, elemental and maceral group composition, degree of vitrinite reflectance show that Bayanteeg coal is a middle rank D mark sub-bituminous coal which is suitable for thermal processing such as pyrolysis and thermal dissolution. 


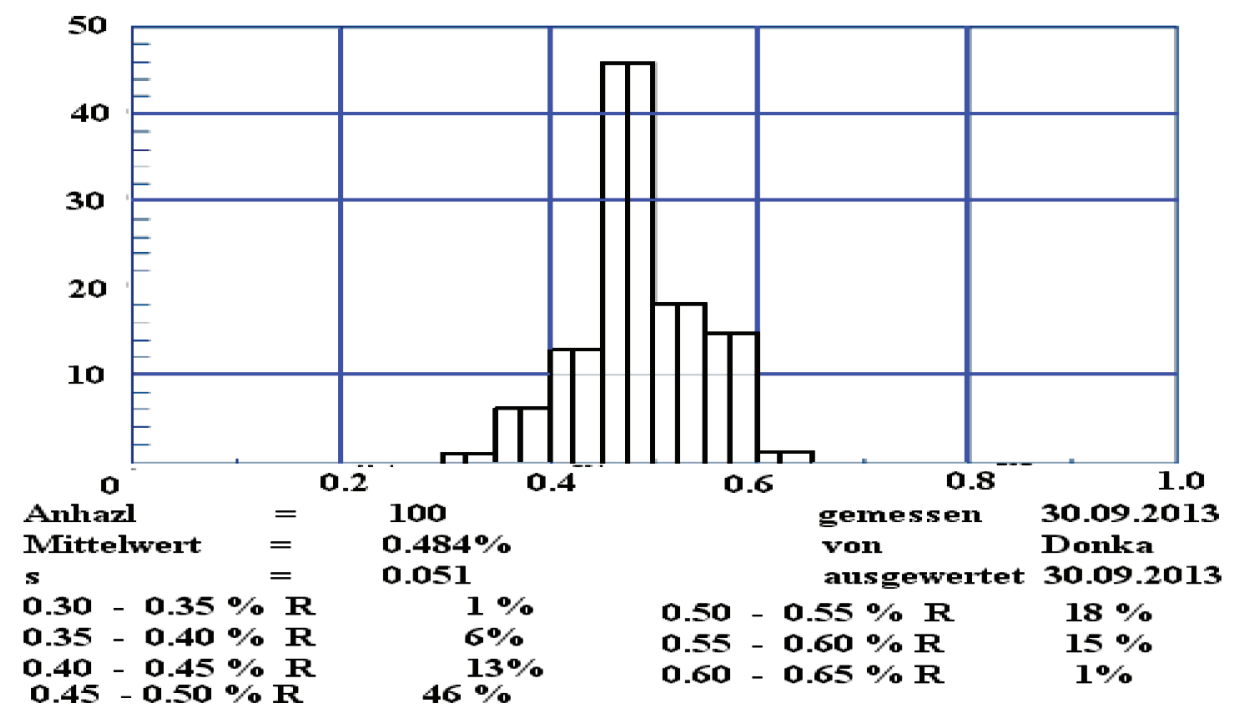

Fig. 2. The diagrams for determination of averaged value of $\% R V_{t}$ for coal of Bayanteeg deposits.

As it is known that brown and subbituminous coals are useful raw material for a gasification and liquefaction technologies [7]. The pyrolysis and thermal dissolution (hydrogen-donor solvent refining) are two different process of liquefaction for obtaining of condensed liquid product from solid fossil fuels. For this reason coals from Bayanteeg deposit have been tested for a pyrolysis experiments aimed to determine a optimal heating temperature of coals in absence of oxygen and the yield of tar (liquid condensed petroleum like product) is chosen as the most important characteristic. The yields of pyrolysis products of Bayanteeg coal including hard residue, tar, pyrolysis water and gas after pyrolysis experiments at different temperatures of heating and constant heating rate $\left(20^{\circ} \mathrm{C} / \mathrm{min}\right.$.) are given in (Table 3$)$.

Table 3.The yields of pyrolysis products of Bayanteeg coal versus heating temperatures

\begin{tabular}{|cccccccc|}
\hline Coal sample & Mass, $g$ & $\begin{array}{c}\text { Temperature, } \\
{ }^{0} \mathrm{C}\end{array}$ & $\begin{array}{c}\text { time, } \\
\text { min }\end{array}$ & $\begin{array}{c}\text { Hard resi- } \\
\text { due, } \%\end{array}$ & Tar, \% & $\begin{array}{c}\text { Water, } \\
\%\end{array}$ & $\begin{array}{c}\text { Gas and } \\
\text { loss, } \%\end{array}$ \\
\hline \multirow{6}{*}{ Bayanteeg } & 1.1773 & 200 & 80 & 95.72 & 0.10 & 0.16 & 4.02 \\
& 0.9541 & 300 & 80 & 94.07 & 1.71 & 0.29 & 3.93 \\
& 0.9995 & 400 & 80 & 69.72 & 12.03 & 4.27 & 13.98 \\
& 1.0067 & 500 & 80 & 66.75 & 14.57 & 5.46 & 13.22 \\
& 1.0003 & 600 & 80 & 63.86 & 13.16 & 3.41 & 19.57 \\
& 1.0025 & 700 & 80 & 61.85 & 10.17 & 2.08 & 25.90 \\
\hline
\end{tabular}

The date in (Table 3) shows that the yield of hard residue is decreased by increasing of heating temperatures, because of increasing thermal decomposition of organic matter of coal at higher temperature. The yield of condensed liquid product (tar) of pyrolysis of coal from Bayanteeg deposit increasing by the heating temperature until $500^{\circ} \mathrm{C}$ in which has a highest yield $14.57 \%$ and then slowly decreasing. Therefore the heating 
temperature $500^{\circ} \mathrm{C}$ was chosen as a optimal heating temperature of pyrolysis of Bayanteeg coal. Also as usually the yields of pyrolysis water and uncondensed gases increased by increasing of heating temperatures.
The results of pyrolysis experiments of Bayanteeg coal show that this coal can be easily tested for thermal dissolution in tetralin as a hydrogen donor solvent. The results of thermal dissolution of this coal is presented in (Table 4).

Table 4. The results of thermal dissolution experiments of Bayanteeg coal

\begin{tabular}{|c|c|c|c|c|c|}
\hline Coal sample & $\begin{array}{c}\text { Donor solvent, } \\
\mathrm{g}\end{array}$ & $\begin{array}{c}\text { Temperature, } \\
{ }^{\circ} \mathrm{C}\end{array}$ & $\begin{array}{c}\text { Solid residue, } \\
\%\end{array}$ & $\begin{array}{c}\text { Liquid product, } \\
\%\end{array}$ & $\begin{array}{c}\text { Gas and loss, } \\
\%\end{array}$ \\
\hline \multirow{3}{*}{ Bayanteeg } & Bayanteeg & 350 & 78.3 & 16.4 & 5.3 \\
& coal:Tetralin & 400 & 27.1 & 44.3 & 28.6 \\
& $1.0: 1.8$ & 450 & 25.0 & 48.1 & 26.9 \\
\hline
\end{tabular}

The yields of thermal dissolution products: hard residue, liquid and gas of Bayanteeg coal at different heating temperatures show that the yield of hard residue is decreasing intensively against the increasing of heating temperatures, because of higher degree of thermal decomposition of coal organic matters at higher temperature. A confirmation of this the summarized yields of liquid and gas productions after thermal dissolution should be increased, because of increasing weight loss of initial coal sample before the thermal dissolution process. Such dependences already have observed in Table 4. The Bayanteeg coal is a middle rank coal with lower thermostabilty and therefore the yields of liquid and gas products are higher. The results of thermal dissolution of Bayanteeg coal in tetralin with constant mass ratio between coal and tetralin $(1: 1.8)$ at $450^{\circ} \mathrm{C}$ show that $48 \%$ of liquid product can be obtained after thermal dissolution of the COM.

The pyrolysis tar was collected by using of a bigger scale retort and then purified from the pyrolysis water for the determination of its chemical composition by GC/MS analysis. Before the GC/MS analysis carried out a column chromatography test of pure tar for determination of the soluble in hexane $(\mathrm{H})$, benzene $(\mathrm{B})$ and dichloromethane $(\mathrm{M})$ fractions of the tar. The yield of these fractions are given in (Table 5).

Table 5. The yield of column chromatography fractions of Bayanteeg coal tar, $\%$

\begin{tabular}{|c|c|c|c|c|c|c|c|c|c|c|}
\hline \multirow{3}{*}{$\begin{array}{c}\text { Tar } \\
\text { sample }\end{array}$} & \multicolumn{10}{|c|}{ Fractions } \\
\cline { 2 - 12 } & \multicolumn{2}{|c|}{ sample } & \multicolumn{1}{c|}{ Hexane $(H)$} & \multicolumn{2}{c|}{\begin{tabular}{c} 
Benzene $(B)$ \\
\cline { 2 - 11 }
\end{tabular}} & $\begin{array}{c}\text { Dichloromehtan } \\
(M)\end{array}$ & \multicolumn{2}{c|}{ Total } \\
\hline 1 & 0.1938 & 100.0 & 0.0143 & 7.27 & 0.0603 & 30.66 & 0.30278 & 14.13 & 0.1024 & 52.06 \\
\hline
\end{tabular}

The date in table 5 show that lowest yield has hexane soluble fraction, highest yield has benzene soluble fraction and dichloromethane fraction has a middle yield in the pyrolysis tar of Bayanteeg coal. The GC/MS analysis of each separated H,B and $M$ fractions have been carried out by using of a chromatomass spectrometric system Agilent 7890A, Agilent 5975C GCMS and the chemical compositions of each fractions are shown in (Fig. 3,4 and 5). 


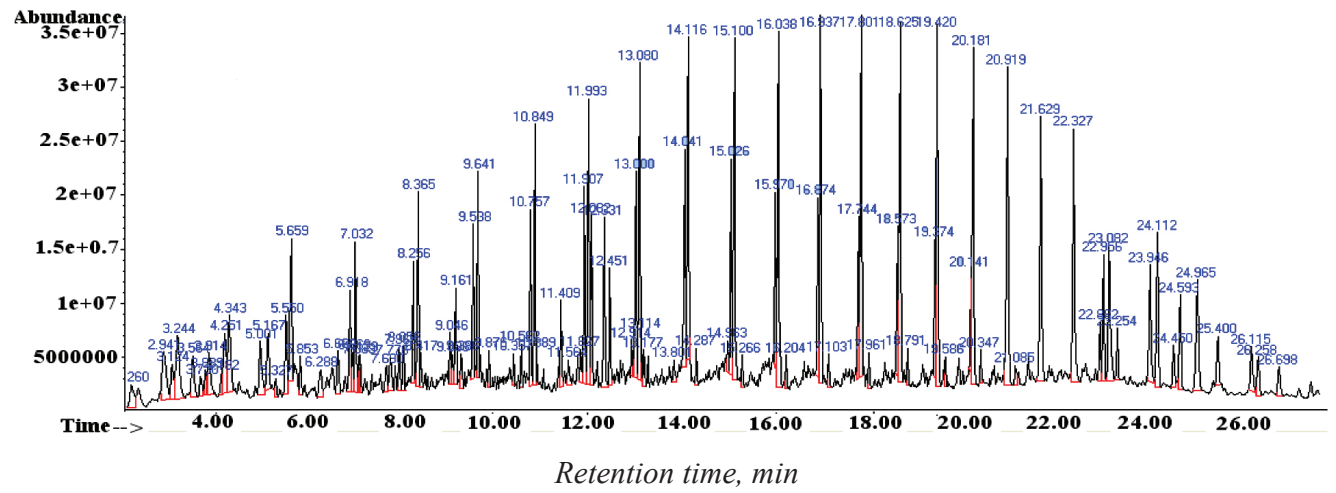

Fig. 3. GC/MS chromatogram of hexane soluble fraction.

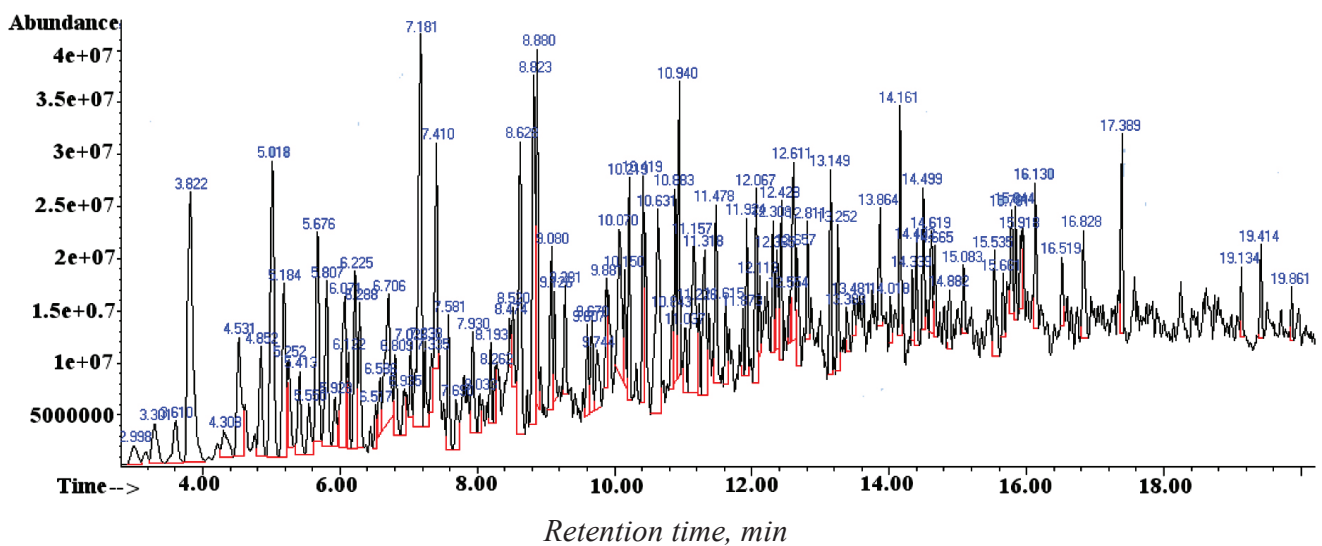

Fig. 4. GC/MS chromatogram of benzene soluble fraction.

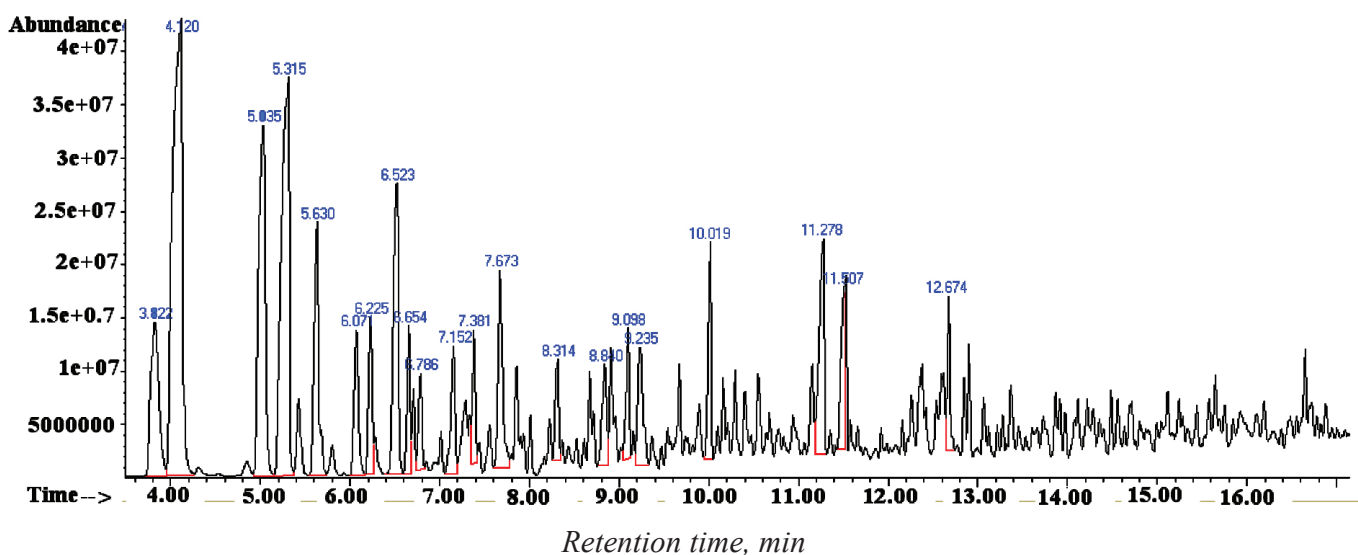

Fig. 5. GC/MS chromatogram of dichlorometane soluble fraction. 
The results of GC/MS analysis of hexane soluble fraction of the pyrolysis tar of Bayanteeg coal show that 37 peak of organic substances have been identified from all 100 registered peaks. For the benzene soluble fraction have been identified 38 peak of organic substances from all 100 registered peaks and for the dichlorometane soluble fraction have been identified all registered 23

\section{CONCLUSIONS}

On the basis of proximate, ultimate, petrographic analysis have been confirmed that the Bayanteeg coal is a middle-rank subbituminous coal of D mark and it is suitable for thermal processing including pyrolysis and thermal dissolution.

The results of pyrolysis experiment of Bayanteeg coal show that $66,75 \%$ of coal organic mass remained as a hard residue after pyrolysis. The yield of all liquid and gas products is $33,25 \%$ at the optimal heating temperature $500^{\circ} \mathrm{C}$, which is showing that there was an intensive thermal dissolution of the coal organic mass with higher degree of conversion.

The results of thermolysis of Bayanteeg coal in tetralin with constant mass ratio between coal and tetralin $(1: 1.8)$ at $450^{\circ} \mathrm{C}$ show that $48.0 \%$ of liquid product can be obtained after thermal dissolution of the coal organic mass. peak of organic substances. The list (three big Tables) of all registered and identified organic substances for each fractions are not given in this paper. The identified most important organic substances in 3 fractions are alkanes, alkenes, phenols, alkylphenols, alkylbenzenes, alkylphenantranes, naphthaline, alkylnaphthalines, indane, indanol, eikozane and so on.
The results of column chromatography of pure tar of Bayanteeg coal show that lowest yield $-7.27 \%$ has hexane soluble fraction, highest yield-30.66\% has benzene soluble fraction and dichloromethane fraction has a middle $-14.13 \%$ yield in the pyrolysis tar.

The results of GC/MS analysis of hexane soluble fraction of the pyrolysis tar of Bayanteeg coal show that 37 peak of organic substances have been identified from all 100 registered peaks. For the benzene soluble fraction have been identified 38 peak of organic substances from all 100 registered peaks and for the dichlorometane soluble fraction have been identified all registered 23 peak of organic substances. The identified most important organic substances in 3 fractions are alkanes, alkenes, phenols, alkylphenols, alkylbenzenes, alkylphenantranes, naphthaline, alkylnaphthalines, indane, indanol, eikozane and so on.

\section{REFERENCES}

1. Purevsuren B. (2007) Coal is the main source of energy. In Abstracts of papers, Second Korean and Mongolian Energy Conference, Yonsei University, Seoul, 13.

2. Purevsuren B., Davaajav Ya., Erdenechimeg R. (2010) Investigation on largest coal deposits in Mongolia. Monograph, Toonotprint., p. 212.

3. Tsedevsuren Ts. (1981) Hydrogenation of Bayanteeg coal of Mongolia. J. Chemistry of Solid Fuels RAS., 6, 17.

4. Avid, B. Purevsuren, B., et al., J. Therm. Anal. Calorimetry, 2002, vol. 68, p. P. 877.

5. Kolesnikova, S.M., Kamenskii, E.S., Kuznetsov, P.N., et al., Khim. Tverd. Topl. (Moscow), 2012, no. 5, p. 29.

6. Purevsuren B, Davaajav Ya, P. N. Kuznetsov, and S. M. Kolesnikova Composition and Technological Properties of Coals from Mongolian Deposits // Solid Fuel Chemistry, 2012, Vol. 46, No. 3, pp. 149-152. 
7. Purevsuren B., Davaajav Ya., Erdenechimeg R. (2010) Investigation on largest coal deposits in Mongolia. Monograph, Toonotprint., 212.

8. Taylor G.H., Teichmüller M., Davis A., et al.(1998) J. Organic Petrology, Gebr. Borntraeger Stuttgart, 704.

9. Davaajav Ya,(2006) Investigation on Pyrolyisis of Some Organic Raw Materials, Dissertation, p.36. University of Ulaanbaatar, Mongolia. 